IJRMMS-D-14-00256 - edited and approved by editor

Technical Note

\title{
A Method to Determine Pore Compressibility Based on Permeability Measurements
}

\author{
Kegang Ling ${ }^{1 *}$, Jun $\mathrm{He}^{1}$, Peng Pei ${ }^{1}$, Jun $\mathrm{Ge}^{1}$ and Xiao $\mathrm{Ni}^{2}$ \\ ${ }^{1}$ University of North Dakota, Grand Forks, North Dakota, United States \\ ${ }^{2}$ China University of Petroleum, Beijing, China
}

*Corresponding Author: Kegang Ling

Email: kegang.ling@engr.und.edu

\section{Introduction}

With the decline in conventional oil and gas production worldwide, petroleum exploration and production from unconventional oil and gas resources have gained great momentum throughout the world to fill the gap between ever-increasing demand of energy and decreasing production of conventional reservoirs. Knowledge of geomechanical properties of target reservoirs ensures producing hydrocarbons from unconventional resources safely, environmental friendly, and economically. Pore compressibility is one of key parameters in designing oil and gas well drilling and completion, modeling fluids flow in reservoir, and forecasting well production. There are two methods to obtain pore compressibility. One is direct measurement; another is indirect measurement. Direct measurement measures compressibility through uniaxial or triaxial stress experiment. Indirect measurement estimates compressibility from correlations or other measurements. The importance of compressibility is reflected by numerous investigations attempting to evaluate it accurately.

Carpenter and Spencer [1] measured compressibility of consolidated oil-bearing sandstones collected from East Texas oil field at reservoir conditions. Hall [2] conducted tests to measure limestone and sandstone compressibilities in the same manner as those reported in the Carpenter and Spencer's 
study. He developed correlation to estimate rock compressibility through porosity. Hall found that ignoring rock compressibility can lead to a 30-40\% overestimation of oil in place. Fatt [3] studied the variation of rock compressibility at different pressures. Fatt [4] found that rock compressibility is a function of pressure and cannot be correlated to porosity. van der Knaap [5] proved the nonlinear stressvolume relations of elastic porous media through theoretical and experimental analysis. Harville and Hawkins [6] indicated that rock compressibility of geopressured gas reservoir is higher than that of normally pressured reservoir. Newman [7] measured compressibility of 256 samples taken from consolidated and unconsolidated rocks and compared with Hall's [2] and van der Knaap's [5] studies. Greenwald and Somerton [8] measured compressibility of Berea, Bandera, and Boise sandstones. Comparison of these compressibilities to those available in the literature indicated qualitative agreement for each of the sandstone types and for their relative behavior. Greenwald and Somerton [9] developed a semi-empirical model to calculated rock compressibility. Variables required for their model are initial porosity, clay content, a pore shape factor, a length and aspect ratio of representative cracks in the matrix grains, the volumetric density of these cracks, and the mineralogical composition of the sample along with the elastic moduli of the minerals present. Hsieh et al. [10] presented a general solution for the transient pulse test measuring the hydraulic properties of low permeability rock samples. In their analyses, dimensionless variables were applied to determine rock hydraulic properties graphically. Zimmerman et al. [11] developed relations to evaluate rock compressibility from confining and pore pressures. They verified relations through experimental measurements on Berea, Bandera, and Boise sandstones. Poston and Chen [12] determined formation compressibility and gas in place in abnormally pressured reservoirs simultaneously using material balance. Chalaturnyk and Scott [13] summarized different geomechanical test procedures and analyzed the results. Khatchikian [14] proposed a method using the Gassman equation and reservoir parameters evaluated through log analysis. Wang and Hart [15] used the sensitivity coefficients of pressure with respect to permeability and specific storage to estimate the experimental errors of permeability and specific storage measured from the transient pulse techniques. They concluded that permeability is more accurate the specific storage in the pulse decay method because permeability is more sensitive to the ratio of sample storage to upper reservoir storage. Green and Wang [16] precisely defined the specific storage coefficient under conditions of general stress, strain, and pressure with incorporation of stress-strain boundary conditions for the elementary volume. With that, the specific storage coefficient can be used as one of the poroelastic constants. Yildiz [17] predicted rock compressibility using production data. His method is the same as Poston and Chen's [12] method. Macini and Mesini [18] measured sandstone and carbonate compressibility by both static (deformation tests) and dynamics (acoustic tests) investigations. Their study showed that compressibility is not constant, but is a function of reservoir pressure. Hart and Wang [19] presented a method to 
determine the drained and undrained bulk compressibilities, the Skempton's $B$ coefficient, the hydraulic conductivity, and the three-dimensional unconstrained specific storage of Barre granite from one test on a single sample. Marchina et al. [20] measured compressibility of reservoir rocks of a heavy oil field under in-situ conditions. Li et al. [21] presented a model to calculate rock compressibility using the elastic modulus and the Poisson's ratio. Suman [22] estimated rock compressibility under reservoir conditions at different depleted stages using sonic velocity derived from 4D seismic.

Because direct measurement of rock compressibility is time consuming and cost expensive. Estimation of rock compressibility from other readily available experimental data, such as sonic velocity and permeability experiment, is highly demanded. In this study, we developed a method to determine the pore compressibility using permeability experimental data. With known pore compressibility, bulk compressibility can be estimated. The combination of the proposed method with direct measurement can be employed to ensure the reliability of the direct measurement and to quantify the uncertainty resulting from lab and human errors, irregular core plug, and/or non-uniform deformation.

\section{New Method to Estimate Rock Compressibility}

In this study, lab data from permeability experiment are used to estimate pore compressibility. To better understand the principle used for permeability measurement, it is necessary to derive the governing equation of fluid flow through a cylinder-shape core as shown in Fig. 1. Oil or gas can be used as the testing fluid. Followings are the derivation of governing equation for gas flow. In case of oil, the derivation is similar.

Following assumptions are made to derive the equation: (a) The core is homogeneous. (b) Rock properties are constant. (c) Darcy flow in the core; the non-Darcy flow is insignificant and can be ignored. (d) Isothermal gas flow in the core

To derive the partial differential equation for linear gas flow through the core, mass conservation, Darcy law, and equations of state are applied. To get the general solution to the partial differential equation, the concept of gas pseudopressure is introduced. Considering a control volume in Fig. 1, the mass conservation gives

$$
\frac{v_{x} \rho_{g^{-}} x+\Delta x}{-\left.v_{x} \rho_{g}\right|_{x}}=\frac{\left.\rho_{g}\right|_{t+\Delta t}-\left.\rho_{g}\right|_{t}}{\Delta t}
$$

where

$t$ is the time, $\Delta t$ is the time period, $v_{x}$ is the gas velocity in the $x$-direction, $\Delta x$ is the incremental distance in $x$-direction, $\phi$ is the porosity, and $\rho_{g}$ is the gas density.

Taking the limit of both hand-sides yields 


$$
\frac{\square\left(v_{x} \rho_{g}\right)}{\square x}=\frac{\square\left(\rho_{g}\right)}{\square t}
$$

Gas velocity through core can be expressed as

$$
v_{x}=\frac{k}{\mu_{g}} \frac{\square p}{\square x}
$$

where $k$ is the permeability, $p$ is the pressure, and $\mu_{g}$ is the gas viscosity. Gas density can be calculated by the real gas law,

$$
\rho_{g}=\frac{M}{R T} \frac{p}{Z}
$$

where $M$ is the molecular weight, $R$ is the universal gas constant, $T$ is the temperature, and $z$ is the gas compressibility factor .

Substituting Eqs. (3) and (4) into (2) yields

$$
\frac{\square\left(\frac{k \square p}{\mu_{g} \square x} \frac{M}{R T} \frac{p}{z}\right)}{\square x}=\frac{\square\left(\frac{M p}{R T z}\right)}{\square t}
$$

With the constant permeability assumption, Eq. (5) can be recasted to

$$
\frac{\square\left(\frac{p \quad \square p}{\mu_{g} \square x}\right)}{\square x}=\frac{1}{k}\left[\frac{\square\left(\frac{p}{z}\right)}{\square t}+\frac{p}{z} \frac{\square}{\square t}\right]
$$

In order to simplify Eq. (6), Al-Hussainy [23] introduced the concept of gas pseudopressure, which is

$$
m(p)=\int_{p_{b}}^{p} \frac{2 p}{\mu_{g} z} d p
$$

where $m(p)$ is the gas pseudopressure, and $p_{b}$ is the base pressure. For isothermal gas flow in the core, we have

$$
\frac{\square[m(p)]}{\square x}=\frac{2 p}{\mu_{g} Z} \frac{\square p}{\square x}
$$

and

$$
\frac{\square[m(p)]}{\square t}=\frac{\square[m(p)]}{\square p} \frac{\square p}{\square t}=\frac{2 p}{\mu_{g} z} \frac{\square p}{\square t}
$$

The coefficient of isothermal compressibility of gas and pore compressibility at constant confining pressure are defined as

$$
C_{g}=-\frac{1}{V_{g}}\left(\frac{\square V_{g}}{\square p_{p}}\right)_{p_{c}}
$$

and

$$
C_{p p}=\frac{1}{V_{p}}\left(\frac{\square V_{p}}{\square p_{p}}\right)_{p_{c}}
$$


where $C_{g}$ is the gas isothermal compressibility, $C_{p p}$ is the pore compressibility at constant confining pressure, $p_{p}$ is the pore pressure, $p_{c}$ is the confining pressure, $V_{g}$ is the gas volume, $V_{p}$ is the pore volume, and $V_{g}=V_{p}$.

In the experiment the temperature and the confining pressure are kept constant. Recalling real gas law we have

$$
\left(\frac{\square V_{g}}{\square p_{p}}\right)_{p_{c}}=n R T \frac{p\left(\frac{\square z}{\square p}\right)_{T}-z}{p^{2}}
$$

and

$$
-\frac{1}{V_{g}}=-\frac{p}{z n R T}
$$

where

$n$ is the number of moles of gas. Substituting Eqs. (12) and (13) into (10) gives

$$
C_{g}=\frac{1}{p}-\frac{1}{z}\left(\frac{\square z}{\square p}\right)_{T}
$$

Applying chain rule we have

$$
\frac{\square\left(\frac{p}{z}\right)}{\square t}=\frac{\square\left(\frac{p}{z}\right)}{\square p} \frac{\square p}{\square t}=\frac{p}{z} c_{g} \frac{\square p}{\square t}
$$

Substituting Eqs. (8), (9), (11) and (15) into (6) gives

$$
\frac{\square^{2}[m(p)]}{\square x^{2}}=\frac{\mu_{g}\left(C_{g}+C_{p p}\right)}{k} \frac{\square[m(p)]}{\square t}
$$

Equation (16) is the governing equation for linear gas flow through core, where $\frac{\mu_{g}\left(C_{g}+C_{p p}\right)}{k}$ is the diffusivity coefficient and $\left(C_{g}+C_{p p}\right)$ represents the storage. Under the small pressure drop conditions, the coefficient of right-hand-side of Eq. (16) can be considered as constant and Eq. (16) can be treated as a linear partial differential equation. Lee [24] proposed a method to calculate the radius of investigation in radial system during transient flow using the pressure disturbance concept. Similar principle is applied here to estimate the propagation of pressure through the core. At the beginning of experiment, the upstream and downstream pressures in Fig. 1 are in equilibrium. The upstream pressure is increased instantaneously to introduce a pressure disturbance into the core. The disturbance at location $x$ will reach its maximum at time $t_{\mathrm{m}}$ after introducing the pressure disturbance. According to the general solution to Eq. (16), for an instantaneous pressure disturbance in an infinite linear system [25], the pressure at location $x$ is

$$
m(p)-m\left(p_{i}\right)=\frac{Q}{\sqrt{t}} \exp \left[\frac{-x^{2}}{4 \frac{k}{\mu_{g}\left(C_{g}+C_{p p}\right)} t}\right]
$$


where $p_{i}$ is the initial pressure, $Q$ is the strength of the instantaneous pressure disturbance, $t_{m i}$ is the time at which the pressure disturbance is a maximum at location $x$.

$Q$ is a constant, related to the strength of the instantaneous pressure disturbance. The time $t_{\mathrm{m}}$ at which the pressure disturbance is a maximum at $x$, can be obtained by differentiating and setting equal to zero:

$$
d[m(p)] d t=\frac{Q}{2} \exp \left[\frac{-x^{2}}{4 \frac{k}{\mu_{g}\left(C_{g}+C_{p p}\right)} t}\right] \frac{1}{(\sqrt{t})^{3}}\left[\frac{x^{2}}{2 \frac{k}{\mu_{g}\left(C_{g}+C_{p p}\right)} t}-1\right]=0
$$

Since $t=0$ is a trivial solution to Eq. (18), Eq. (18) can be simplified to

$$
\frac{x^{2}}{2 \frac{k}{\mu_{g}\left(C_{g}+C_{p p}\right)} t}-1=0
$$

or

$$
C_{p p}=\frac{2 t k}{\mu_{g} x^{2}}-C_{g}
$$

Expressing Eq. (20) in SI units we have

$$
C_{p p}=\frac{2000.106 t k}{\mu_{g} x^{2}}-C_{g}
$$

where permeability $k$ is in $\mathrm{m}^{2}$, porosity $\phi$ is dimensionless (in fraction), viscosity $\mu$ is in $\mathrm{mPa}$ s, pore and gas compressibilities $C_{g}$ and $C_{p p}$ are in $\mathrm{Pa}^{-1}$, time $t$ is in second, and location (or distance) $x$ is in meter.

Equation (17) is an approximation and can be used for a finite length sample as pointed out by Lee [24]. Lee [24] applied the radius-of-investigation concept to determine the location of pressure disturbance when it propagates radially in a cylindrical reservoir. The radius-of-investigation concept can be applied to the case that pressure propagates linearly through a core, which is the case in this study. If we take the core length as the pressure disturbance propagating distance, or $x=L$, rock compressibility can be estimated from Eq. (20) or (21) given porosity, permeability, gas viscosity and compressibility, and the time for pressure disturbance travel through the core. The aforementioned derivation of Eq. (20) or (21) uses gas as test fluid to measure low permeability rocks. It should be noted that liquid will be used for high permeability rocks. Similarly, liquid properties can be combined with porosity and permeability, and pressure disturbance travel time to calculate rock compressibility. Porosity and core length can be measured easily. Gas viscosity and pore compressibility can be calculated with given gas composition, pressure, and temperature. Time of pressure disturbance travel through core can be obtained by recording the time when pressure disturbance is generated and the time it travels to downstream of the core. Permeability can be obtained by steady-state or unsteady-state test such as 
oscillating pulse and pulse decay methods. Following is the discussion of oscillating pulse method used in this study.

\section{Determination of rock permeability using complex pore pressure transients}

The complex pore pressure transients are used to determine rock permeability [26]. The analyses of complex (arbitrary) transients proposed by Boitnott extend the working range of transient techniques such as pulse decay and sinusoidal oscillation without changing system specifications or sample dimensions. By properly selecting suitable transients, the technique is able to measure a wide range of permeability accurately in relatively short time. Different options are available when complex transients are used. These options include ASPIKE transient, CUSP transient, MULTISINE transient, and ASAW transient. Each transient has its own characteristics which offer different advantages for various permeabilities.

Figure 2 shows the use of ASAW transient, which is one of the complex transients, to measure the permeability of a Bakken rock sample and how the upstream and downstream pressures change during the test. A constant pressure is applied at the upstream end of the core plug and the pressure at the downstream end of the core plug is built up. Point ' $\mathrm{B}$ ' marks the time that the pressure disturbance arrive downstream end of core. The time period from 0 to point ' $\mathrm{B}$ ' is the time used in Eq. (20) or (21) to calculate rock compressibility. The complex transients start when the initial pressure equilibration is reached at point ' $\mathrm{A}$ ', and ends at the point ' $\mathrm{C}$ '.

In this study, Autolab-1500 system developed by New England Research, Inc. was used to measure the rock permeability. The equipment provides complex transient technique to allow it measure different rock permeabilities. This equipment can also be used to measure rock geomechanical properties such as Young's modulus, Poisson's ratio, Biot's coefficient, through triaxial stress experiments.

\section{Model verification and applications}

To verify the proposed model and evaluate its accuracy, lab measurements of nine cores are used in this investigation. In the measurement, the permeability experiment as Fig. 2 is conducted and the pore compressibility is calculated by Eq. (21). Triaxial stress experiment is performed to measure bulk compressibility directly. In this study, bulk compressibilities under constant pore pressure and constant confining pressure are measured (Table 1). Then bulk compressibilities are used to calculate pore compressibility through [11]

$$
C_{p p}=\frac{C_{b c}-(1+) C_{r}}{}
$$

where 


$$
C_{r}=C_{b c}-C_{b p}
$$

where $C_{b c}$ is the bulk compressibility at constant pore pressure, $C_{b p}$ is the bulk compressibility at constant confining pressure, and $C_{r}$ is the rock matrix compressibility. Then pore compressibility obtained from these two methods is compared and relative error is analyzed.

The equipment used in this study is a complete laboratory system with three integrated components. (a) A pressure vessel and the associated pressure intensifiers to generate stresses (pressures) on a test specimen. (2) An electronics console that interfaces with the mechanical system to precisely control the state of stress and to condition and amplify signals from the transducers and devices measuring force, pressure, displacement, strain, temperature, velocity, and resistivity. (3) A data acquisition system, which generates reference signals to control the equipment, to acquire data, and to process the data collected on each experiment.

The schematic diagram of core holder and hydraulic system in the equipment is depicted in Fig. 3. One temperature transducer (TT1) is used to measure the temperature. Four pressure transducers, PT1, PT2, PT3, and PT4, are used to measure upstream pressure, confining pressure at the flank of the core, downstream pressure, and axial pressure at the ends of the core, respectively. The measuring temperature ranges from $296.15 \mathrm{~K}\left(23{ }^{\circ} \mathrm{C}\right)$ to $297.15 \mathrm{~K}\left(24^{\circ} \mathrm{C}\right)$. The upstream pressure is maintained near $2.768 \times 10^{7}$ $\mathrm{Pa}$ (4000 psi), while downstream pressure is pressurized from atmospheric pressure to upstream pressure. When pressure pulse-decay is applied in the upstream reservoir, the pressure difference between peak and valley of pressure pulse varies from $2.034 \times 10^{6} \mathrm{~Pa}(295 \mathrm{psi})$ to $2.448 \times 10^{6} \mathrm{~Pa}(355 \mathrm{psi})$

The permeability measurement procedure is as follows. Connect the end caps, which contain the sensors, to the core. Install the core and the end caps on the core holder. Put the core holder into the pressure vessel. Apply confining pressure by filling the pressure vessel with mineral oil and increasing the fluid pressure. Fill the upstream reservoir with dry nitrogen and then increase the upstream pressure to the desired level. Open the valve to connect the upstream reservoir with the core plug and keep the upstream pressure and the confining pressure constant during the whole test. Monitor and record upstream, downstream, and confining pressures at both flank and ends of core; record temperature simultaneously. Wait until pressure reaches equilibrium at upstream and downstream. Apply oscillating pulse test by generating a pressure pulse at the upstream. Wait for pressure pulse generated at the upstream to propagate to downstream. After pressure pulse reaches downstream, depressurize the system and uninstall the core holder from pressure vessel; the pressure, temperature, and time are monitored and recorded.Remove the core from core holder; disconnect the core from the end caps.

The steps to conduct triaxial stress experiment are as follows. Jacket the specimen with thick copper. Seat the jacket to specimen. Attach strain gages to the test specimen. Secure the sample to the end caps. Place the sample assembly on the base plug of the pressurization system. Connect strain gage 
leads in the base plug. Make sure that the leads for the radial and axial gages are soldered to the appropriate connectors. Insert the sample assembly into the pressure vessel. Fill the pressure vessel with oil. Initiate the AutoLab software. Check the Analog Channel Monitor to ensure that the strain gages are on scale. Now calibrate the strain gages. Increase the differential stress and the confining pressure to the initial value for the triaxial stress measurement; activate the window for the triaxial stress measurement. Fill in the appropriate values in the triaxial stress experiment command module; select the loading rate and set the amplitude of the shear stress cycle, and set the number of loading cycles for the experiment. Select the portion of the stress-strain data that will be processed after the capture. Once all the data is satisfactorily entered into the triaxial stress experiment user interface, apply the load to conduct test. At the conclusion of the test sequence, the processed data are presented. Examine the data and accept them if they are acceptable. The data are now permanently stored. Increase the mean stress to the next value and repeat the cyclic-loading experiment described above. Step-wise increase the confining pressure as desired to determine the elastic constants as a function of confining pressure. At the termination of the test sequence, terminate the data acquisition and end the experiment. Process and review the data that has been collected, recalculate the moduli for different portions of the load/unload cycles, and print a final report.

\subsection{Data Analysis and Comparison}

The pore compressibilities of nine core plugs calculated by the proposed model are compared with those measured by triaxial stress experiment. The comparison indicates that the pore compressibilities from the proposed model are close to those from triaxial stress experiment as shown in Table 1 and Fig. 4. Therefore the proposed model provides a reliable way to determine pore compressibility.

\subsection{Application, Limitations, and Accuracy of the Proposed Method}

The cost to measure pore compressibility can be high and time consuming. The proposed model provides a way to estimate pore compressibility from permeability experimental data in case direct measurement is not available. In the event direct measurement is available, the model can serve as a quality control tool. In particular, the estimated pore compressibility can be used to calculate pore volume change during production and injection, which are used in many reservoir simulators.

The limitation of the proposed method is the sensitivity of the pressure gauge must be high enough to detect small pressure change that indicates the arrival of pressure wave. The accuracy of the proposed model depends on the accuracies of other measured values, such as rock porosity, permeability, core length, and gas compressibilities. The identification of pressure wave arrival at the downstream affects the accuracy as well. With a high resolution pressure gauge and a small downstream reservoir volume, a 
correct capture of pressure wave arrival can be guaranteed. A good estimation of gas viscosity and permeability at measured conditions is also important.

\section{Conclusions}

We have presented a new method to estimate pore compressibility from permeability experimental data, which is often available in special core analysis. Therefore the method developed in this research is a useful tool in the event that no direct measurement is available. Comparison of pore compressibilities obtained by the proposed model with those from direct measurement indicates that the model is reliable. The combination of the new method with triaxial stress measurement makes the estimation of pore compressibility more confident.

\section{Acknowledgment}

The authors are grateful to The Petroleum Engineering Department of University of North Dakota. This research is supported in part by the U.S. Department of Energy (DOE) under award number DEFC26-08NT0005643 and North Dakota EPSCoR Program under award number EPS-0814442. The authors would like to thank the Wilson M. Laird Core and Sample Library and the North Dakota Geological Survey for providing core samples for this study. 


\section{REFERENCES}

[1] Carpenter CR, Spencer GR. Measurements of compressibility of consolidated oil-bearing sandstones. Bureau of Mines RI 3540; 1940.

[2] Hall HN. Compressibility of reservoir rocks. J. Petrol. Tech. 1953; 5:1:17-19.

[3] Fatt I. Compressibility of sandstones at low to moderate pressures. AAPG Bull. 1958; 42: 1924-57.

[4] Fatt I. Pore volume compressibilities of sandstone reservoir rocks. J. Petrol. Tech. 1958;10:3: 6466.

[5] van der Knaap W. Nonlinear behavior of elastic porous media. Petrol. Trans. AIME 1959;216:179187.

[6] Harville DW, Hawkins MF. Rock compressibility and failure as reservoir mechanisms in geopressured gas reservoirs. J. Petrol. Tech. 1969;21:12:1528-30.

[7] Newman GH. Pore-volume compressibility of consolidated, friable, and unconsolidated reservoir rocks under hydrostatic loading. J. Petrol. Tech. 1973;25:2:129-134.

[8] Greenwald RF, Somerton WH. Pore volume compressibility data for Bandera, Berea, and Boise sandstones. Paper SPE 9746-MS. 1981.

[9] Greenwald RF, Somerton WH. A theoretical model for determination of pore volume compressibilities of consolidated sandstones. In: SPE annual technical conference and exhibition. San Antonio, Texas; 4-7 October 1981. Paper SPE 10076.

[10] Hsieh PA, Tracy JV, Neuzil CE, Bredehoeft JD, Silliman SE. A transient laboratory method for determining the hydraulic properties of 'tight' rocks-I. Theory. Int. J. Rock Mech. Min. Sci. Geomech. Abstr. 1981;18:3: 245-252.

[11] Zimmerman RW, Somerton WH, King MS. Compressibility of porous rocks. J. Geophys. Res. 1986;91: B12:12765-77.

[12] Poston SW, Chen HY. The simultaneous determination of formation compressibility and gasin-place in abnormally pressured reservoirs. In: SPE production operations symposium. Oklahoma City, Oklahoma; 8-10 March 1987. Paper SPE 16227. 
[13] Chalaturnyk RJ, Scott JD. Evaluation of reservoir properties from geomechanical tests. J. Canad. Petrol. Tech. 1992;31:5:31-40.

[14] Khatchikian A. Deriving reservoir pore-volume compressibility from well logs. SPE Advanced Technology Series. 1996; 4:1:14-20.

[15] Wang HF, Hart DJ. Experimental error for permeability and specific storage from pulse decay measurements. Int. J. Rock Mech. Min. Sci. 1993;30:7:1173-1176.

[16] Green DH, Wang HF. Specific storage as a poroelastic coefficient. Water Resourc. Res. 1990;26:7:1631-1637.

[17] Yildiz T. Prediction of in-situ formation compressibility from production data. In: SPE/ISRM rock mechanics in petroleum engineering. Trondheim, Norway; 8-10 July 1998. Paper SPE 47379.

[18] Macini P. Mesini E. Static and dynamic reservoir rock compressibility at high pressure. In: SPE Abu Dhabi international petroleum exhibition and conference. Abu Dhabi, United Arab Emirates; 11-14 November 1998. Paper SPE 49549.

[19] Hart DJ, Wang HF. A single test method for determination of poroelastic constants and flow parameters in rocks with low hydraulic conductivities Int. J. Rock Mech. Min. Sci. 2001;38:4:577-583.

[20] Marchina P, Brousse A, Fontaine J, Dano C, Alonso C. In-situ measurement of rock compressibility in a heavy oil Reservoir. In: SPE international thermal operations and heavy oil symposium and western regional meeting. Bakersfield, California; 16-18 March 2004. Paper SPE 86940.

[21] Li C, Chen X, Du Z. A new relationship of rock compressibility with porosity. In: SPE Asia Pacific oil and gas conference and exhibition. Perth, Australia; 18-20 October 2004. Paper SPE 88464.

[22] Suman A. Uncertainties in rock pore compressibility and effects on seismic history matching. Master Thesis, Stanford University, Stanford, California; 2009.

[23] Al-Hussainy R, Ramey HJ, Crawford PB. The flow of real gases through porous media. J. Petrol. Tech. 1966;18:5:624-636.

[24] Lee WJ. Well Testing. Richardson, Texas: Society of Petroleum Engineers; 1982. 
[25] Carslaw HS, Jaeger JC. Conduction of heat in solids. $2^{\text {nd }}$ Ed. Oxford: Clarendon Press; 1959.

[26] Boitnott, GN. Use of complex pore pressure transients to measure permeability of rocks. In: SPE Annual Technical Conference and Exhibition, San Antonio, Texas, USA; 5-8 October, 1997. Paper SPE 38717. 
Table 1. Pore compressibilities calculated from proposed model and measured from triaxial stress experiments

\begin{tabular}{|c|c|c|c|c|c|c|c|c|c|}
\hline & Core 1 & Core 2 & Core 3 & Core 4 & Core 5 & Core 6 & Core 7 & Core 8 & Core 9 \\
\hline $\begin{array}{l}\text { Porosity, } \phi \text {, fractio } \\
\mathrm{n}\end{array}$ & 0.057 & 0.042 & 0.073 & 0.064 & 0.084 & 0.087 & 0.093 & 0.068 & 0.104 \\
\hline $\begin{array}{l}\text { Propagation Time, } \\
t, \mathrm{~s}\end{array}$ & 330.2 & 639.6 & 202.8 & 257.4 & 148.2 & 132.6 & 127.4 & 234 & 104 \\
\hline $\begin{array}{l}\text { Permeability, } k, \\
10^{-19} \mathrm{~m}^{2}\end{array}$ & 1.4805 & 0.5922 & 3.1584 & 2.0727 & 5.1324 & 5.8233 & 6.7116 & 2.5662 & 9.87 \\
\hline $\begin{array}{l}\text { Gas } \\
\text { compressibility, } \\
C_{g}, 10^{-8} / \mathrm{Pa}\end{array}$ & 1.813 & 1.813 & 1.813 & 1.813 & 1.813 & 1.813 & 1.813 & 1.813 & 1.813 \\
\hline $\begin{array}{l}\text { Average gas } \\
\text { pressure, } p, 10^{7} \mathrm{~Pa}\end{array}$ & 2.7670 & 2.7663 & 2.7697 & 2.7704 & 2.7677 & 2.7690 & 2.7683 & 2.7656 & 2.7697 \\
\hline $\begin{array}{l}\text { Gas viscosity, } \\
\mu_{g}, \mathrm{mPa} \text { s }\end{array}$ & 0.0474 & 0.0474 & 0.0474 & 0.0474 & 0.0474 & 0.0474 & 0.0474 & 0.0474 & 0.0474 \\
\hline $\begin{array}{l}\text { Length of the } \\
\text { core, } L, \mathrm{~m}\end{array}$ & 0.0513 & 0.0523 & 0.0516 & 0.0511 & 0.0518 & 0.0513 & 0.0516 & 0.0521 & 0.0518 \\
\hline $\begin{array}{l}\text { Pore } \\
\text { compressibility } \\
\text { under constant } \\
\text { confining pressure } \\
\text { (proposed model), } \\
C_{p p}, 10^{-8} / \mathrm{Pa}\end{array}$ & 0.0885 & 0.0769 & 0.1218 & 0.0914 & 0.1668 & 0.1624 & 0.2175 & 0.1175 & 0.3234 \\
\hline $\begin{array}{l}\text { Bulk } \\
\text { compressibility } \\
\text { under constant } \\
\text { pore pressure } \\
\text { (triaxial stress ), } \\
C_{b c} \text {, } \\
10^{-8} / \mathrm{Pa}\end{array}$ & 0.00794 & 0.00518 & 0.01022 & 0.00825 & 0.01438 & 0.01450 & 0.01941 & 0.00991 & 0.02595 \\
\hline $\begin{array}{l}\text { Bulk } \\
\text { compressibility } \\
\text { under constant } \\
\text { confining pressure } \\
\text { (triaxial stress), } \\
C_{b p} \text {, } \\
10^{-8} / \mathrm{Pa}\end{array}$ & 0.00559 & 0.00284 & 0.00790 & 0.00590 & 0.01202 & 0.01219 & 0.01708 & 0.00756 & 0.02362 \\
\hline Pore & 0.0957 & 0.0653 & 0.1059 & 0.0899 & 0.1407 & 0.1378 & 0.1813 & 0.1088 & 0.2248 \\
\hline
\end{tabular}




\begin{tabular}{|c|c|c|c|c|c|c|c|c|c|}
\hline $\begin{array}{l}\text { compressibility } \\
\text { under constant } \\
\text { confining pressure } \\
\text { (triaxial stress ), } \\
C_{p p} \text {, } \\
10^{-8} / \mathrm{Pa}\end{array}$ & & & & & & & & & \\
\hline Relative error, \% & $-8.20 \%$ & $16.81 \%$ & $14.49 \%$ & $2.06 \%$ & $18.64 \%$ & $18.18 \%$ & $20.30 \%$ & $8.08 \%$ & $44.12 \%$ \\
\hline
\end{tabular}




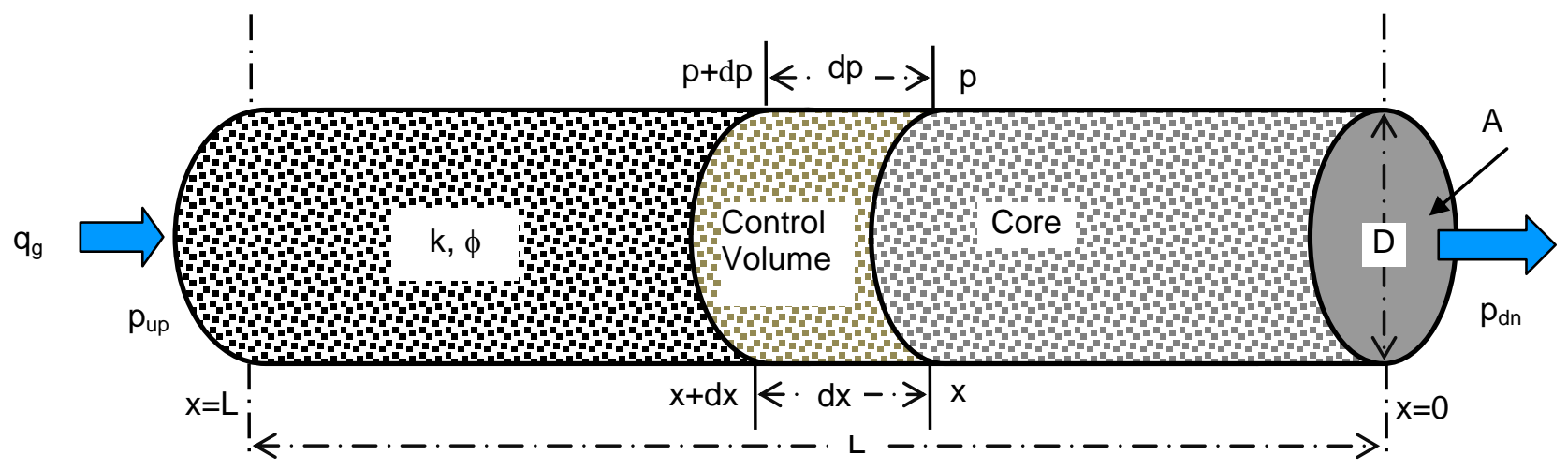

Fig. 1. Gas flows through core during permeability measurement

In Fig. 1,

$\begin{array}{ll}A & =\text { flow area, } \text { or cross-sectional area of core } \\ D & =\text { core diameter } \\ d p & =\text { pressure difference } \\ d x & =\text { difference in } x \text { direction } \\ L & =\text { length of core } \\ p_{d n} & =\text { downstream pressure } \\ p_{u p} & =\text { upstream pressure } \\ q_{g} & =\text { gas flow rate }\end{array}$

Other parameters are defined in the manuscript. 


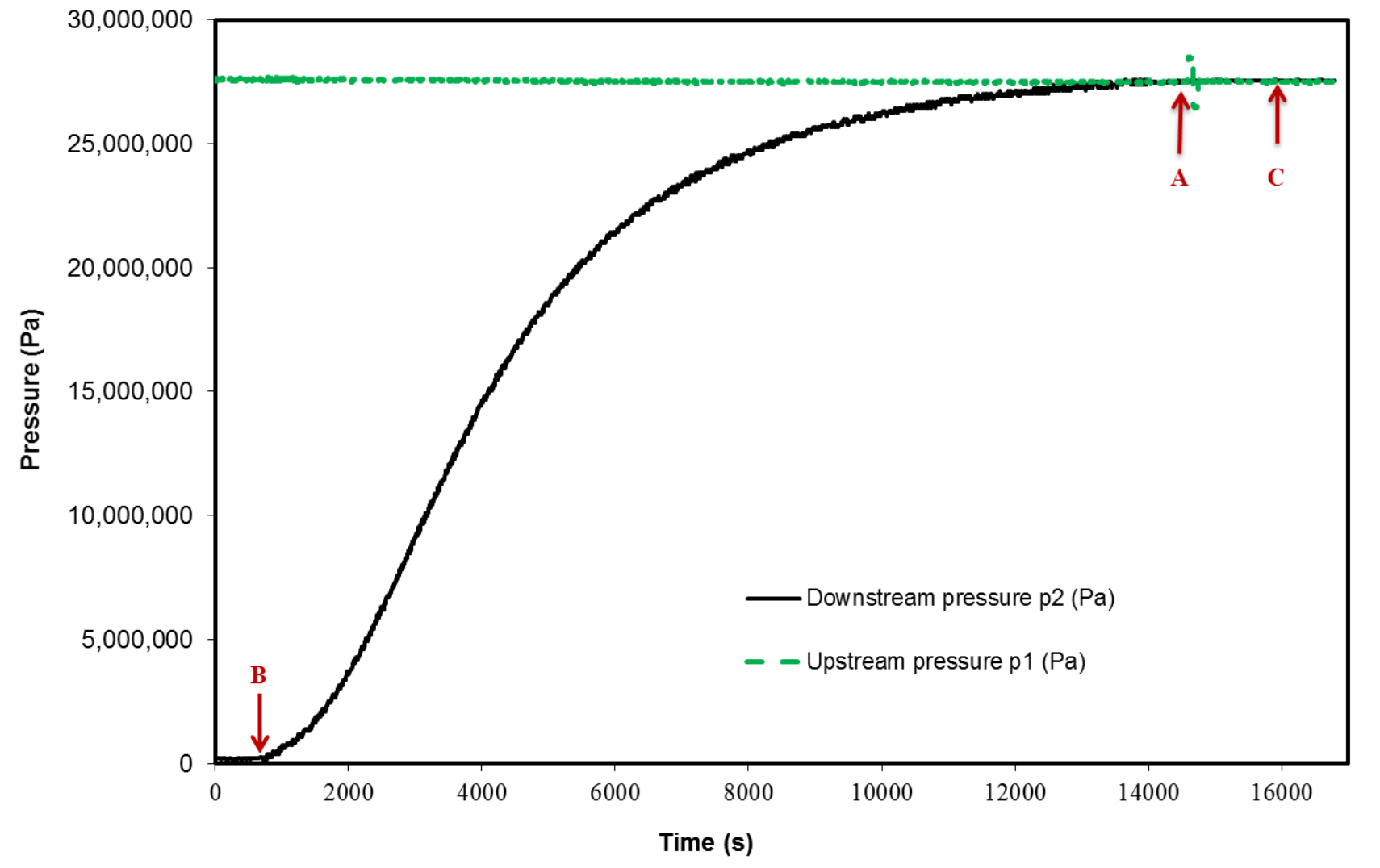

Fig. 2. Changes of the upstream and downstream pressures during one experiment. Point ' $\mathrm{B}$ ' marks the time that the pressure disturbance arrive downstream end of core.Point ' $\mathrm{A}$ ' marks the time that the upstream and downstream pressures reach equilibrium.Point ' $\mathrm{C}$ ' marks the time that the pulse decay experiment ends. 


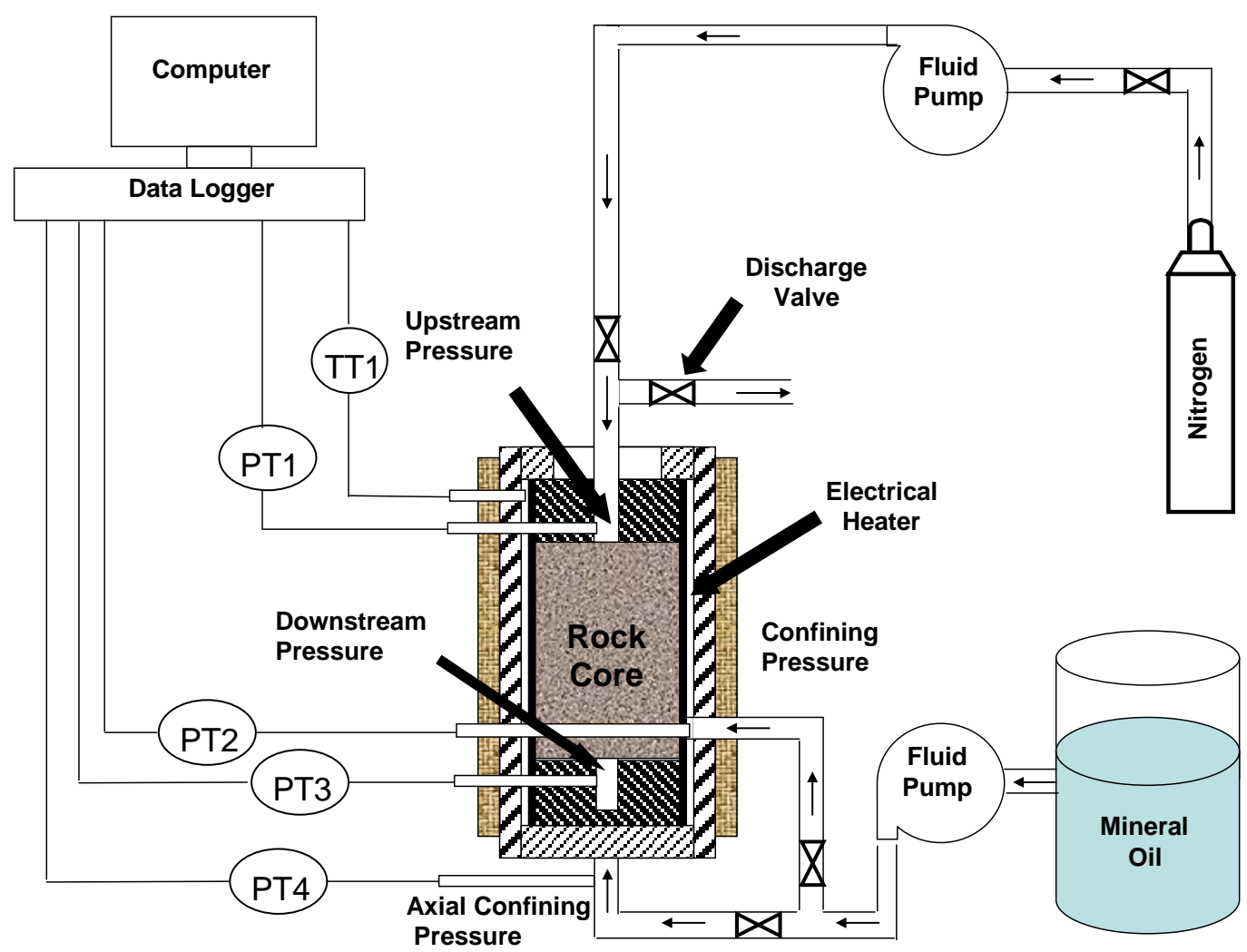

Fig.3. The schematic diagram of the core holder and hydraulic system in the equipment (Autolab 1500) 


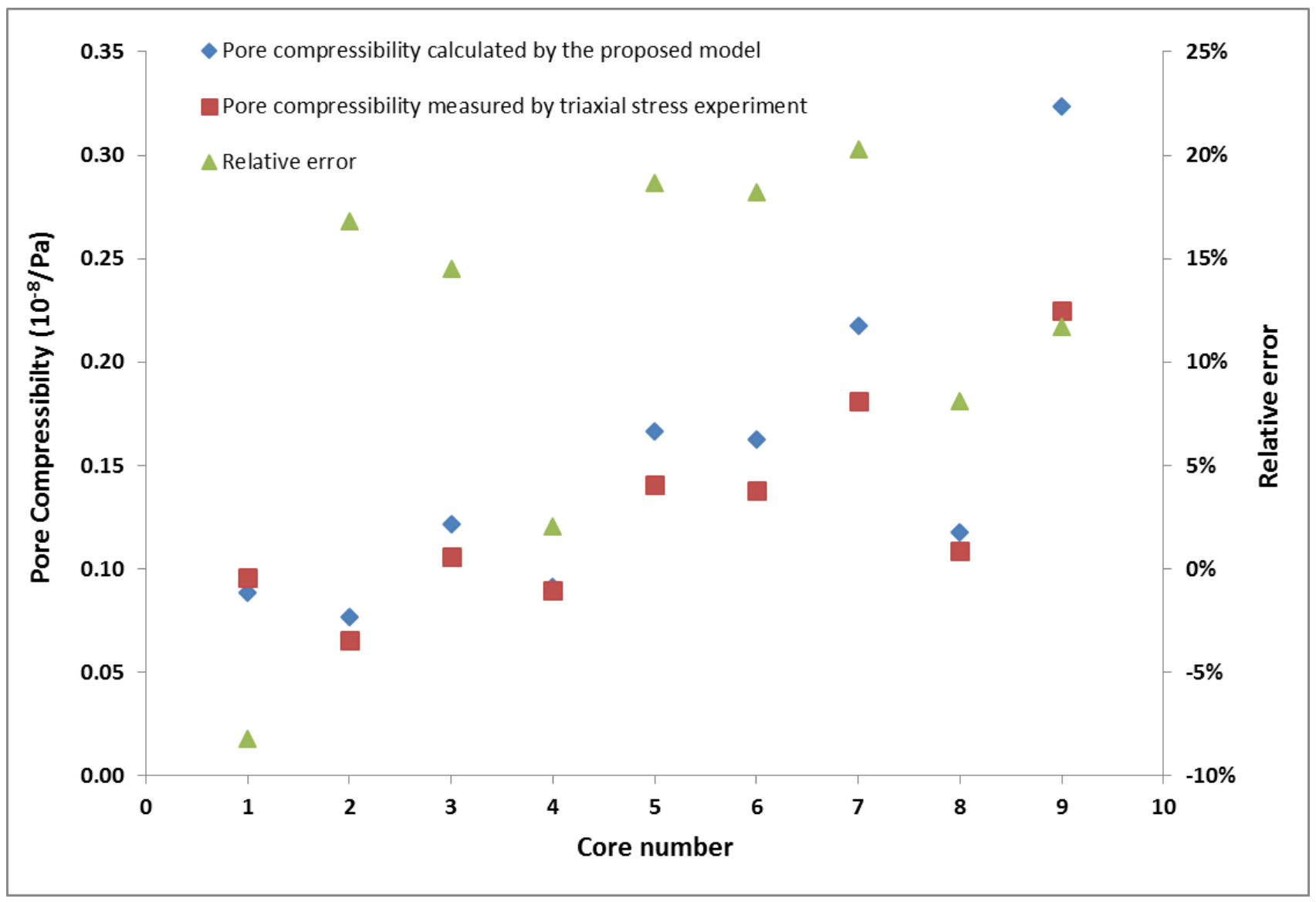

Fig.4. Comparison of pore compressibilities calculated by the proposed model and measured by triaxial stress experiments 